\title{
Radiation Induced Segregation at Grain Boundaries in Steels: NSUF 2018 Milestone Report
}

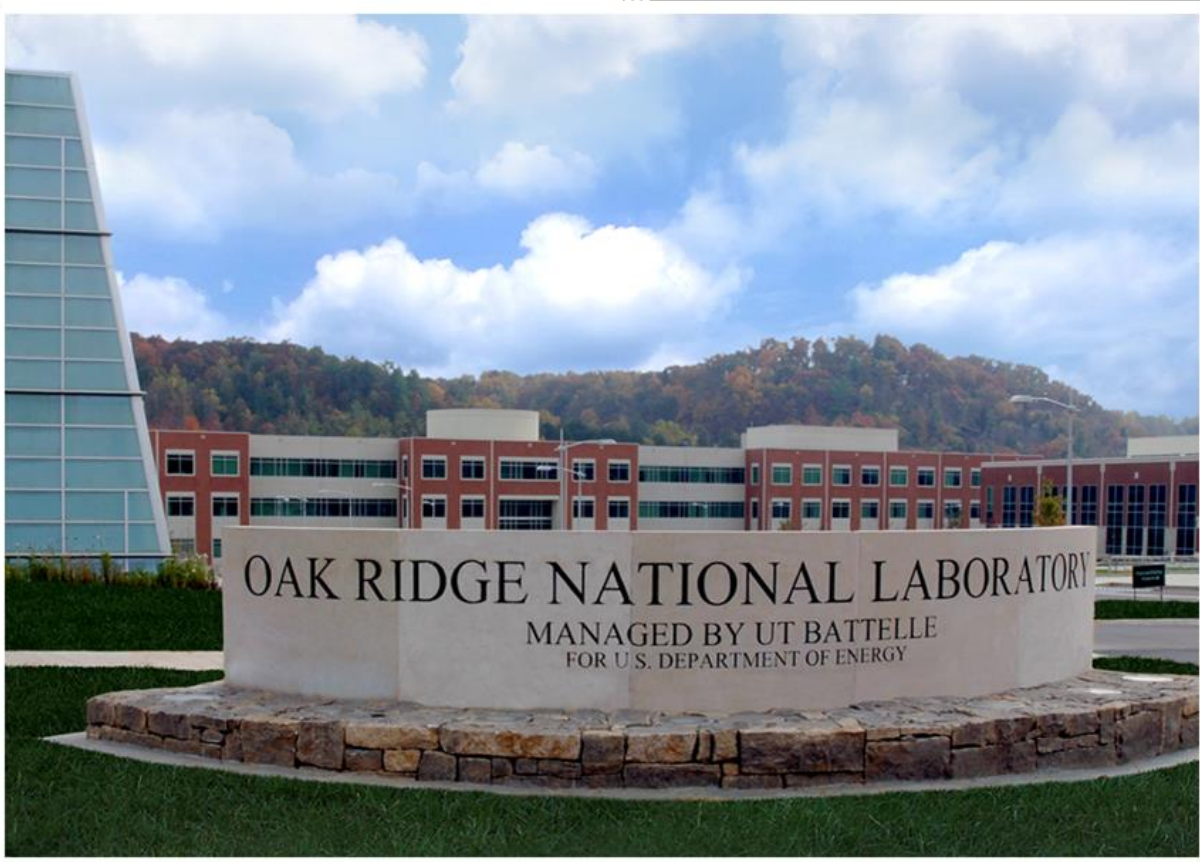

Approved for public release. Distribution is unlimited.

Dalong Zhang

Quinlan Smith Philip Edmondson Kevin Field

Kory Linton

December 2018 


\section{DOCUMENT AVAILABILITY}

Reports produced after January 1, 1996, are generally available free via US Department of Energy (DOE) SciTech Connect.

Website http://www.osti.gov/scitech/

Reports produced before January 1, 1996, may be purchased by members of the public from the following source:

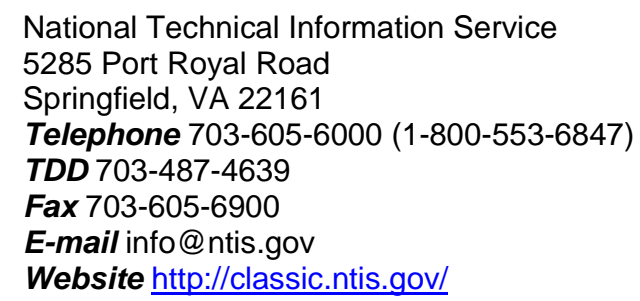

Reports are available to DOE employees, DOE contractors, Energy Technology Data Exchange representatives, and International Nuclear Information System representatives from the following source:

Office of Scientific and Technical Information

PO Box 62

Oak Ridge, TN 37831

Telephone 865-576-8401

Fax 865-576-5728

E-mail reports@osti.gov

Website http://www.osti.gov/contact.html

This report was prepared as an account of work sponsored by an agency of the United States Government. Neither the United States Government nor any agency thereof, nor any of their employees, makes any warranty, express or implied, or assumes any legal liability or responsibility for the accuracy, completeness, or usefulness of any information, apparatus, product, or process disclosed, or represents that its use would not infringe privately owned rights. Reference herein to any specific commercial product, process, or service by trade name, trademark, manufacturer, or otherwise, does not necessarily constitute or imply its endorsement, recommendation, or favoring by the United States Government or any agency thereof. The views and opinions of authors expressed herein do not necessarily state or reflect those of the United States Government or any agency thereof. 
Materials Science and Technology Division

\section{Radiation Induced Segregation at Grain Boundaries in Steels NSUF 2018 Milestone Report}

Dalong Zhang

Quinlan Smith

Philip Edmondson

Kevin Field

Kory Linton

Date Published: December 2018

NSUF Work Package \#: UF-19OR020713

Work Package Manager: Kory Linton

Milestone \#: M3UF-19OR0207132

Prepared by

OAK RIDGE NATIONAL LABORATORY

Oak Ridge, TN 37831-6283

managed by

UT-BATTELLE, LLC

for the

US DEPARTMENT OF ENERGY

under contract DE-AC05-00OR22725 



\section{CONTENTS}

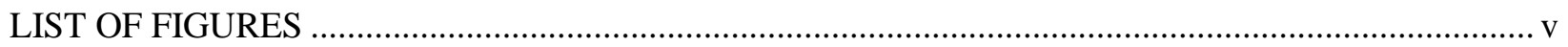

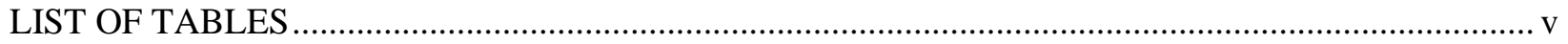

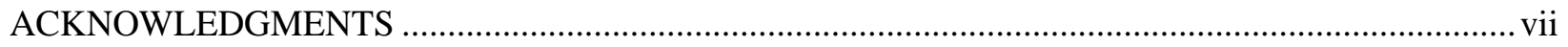

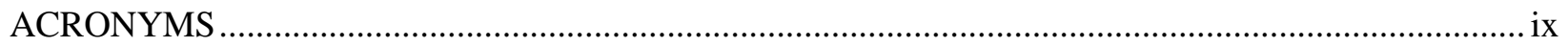

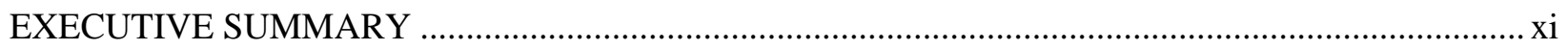

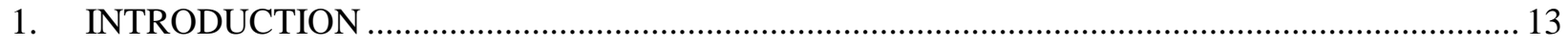

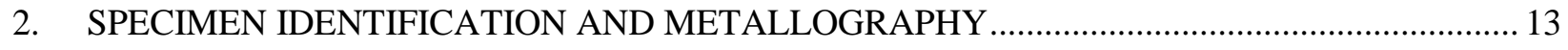

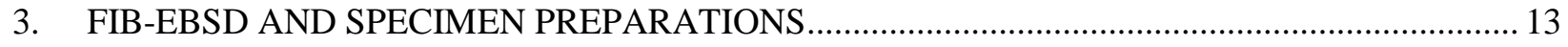

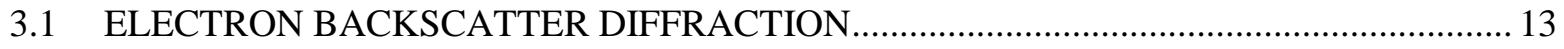

3.2 PREPARATION OF APT SAMPLES ............................................................... 14

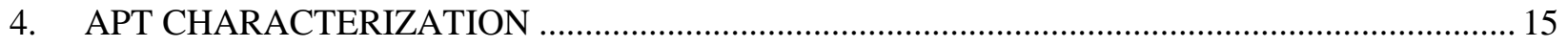

5. CONCLUSION AND FURTHER ANALYSIS .............................................................. 17

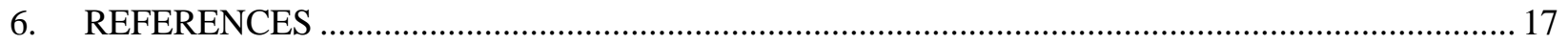





\section{LIST OF FIGURES}

Figure 1: (a). Selected area EBSD map of CINR specimen AS13 to locate suitable low angle grain boundaries (LAGBs). (b). Enlarged SEM view of one selected LAGB that was subsequently lifted out for APT sample preparation by FIB. (c). The misorientation angle of the selected LAGB was $3.4^{\circ}$.

Figure 2: (a). Selected area EBSD map of CINR specimen AS13 to locate suitable high angle grain boundaries (HAGBs). (b). SEM view of one selected HAGB that was subsequently lifted out for APT sample preparation by FIB. (c). The misorientation angle of the selected "HAGB" was $9.1^{\circ}$. Note that this misorientation angle was lower than $15^{\circ}$ but larger than $5^{\circ}$, and its behavior differed from LAGB with misorientation angle lower than $5^{\circ}$, so it was considered HAGB in the context of this report.

Figure 3: Reconstructions of APT datasets, represented by the isosurface of major and minor alloying elements at varying atomic concentrations, i.e., $\mathrm{Cr}$ at $24 \%, \mathrm{Ni}$ at $15 \%, \mathrm{Mn}$ at $2.5 \%, \mathrm{Si}$ at $3 \%, \mathrm{Cu}$ at $1 \%, \mathrm{P}$ at $0.5 \%$, as well as overlays of $\mathrm{Cr}-\mathrm{Ni}-\mathrm{Si}$ to better reveal the profile of grain boundaries. Upper row: low angle grain boundary, the white arrow points to the approximate location of the grain boundary; Lower row: "high angle" grain boundary.

Figure 4: Quantification of radiation induced segregation (RIS) by intersecting grain boundary with a $10 \mathrm{~nm}$ (diameter) $* 20 \mathrm{~nm}$ (height) cylinder region of interest (ROI), then plotting the concentration of alloying elements as a function of distance from the approximate grain boundary plane. (a). LAGB, see the ROI cylinder nearly at the center of reconstruction volume in the insert; (b). HAGB, the ROI cylinder at the center-right of the reconstruction volume in the insert.

\section{LIST OF TABLES}

Table 1: Samples identified for characterization. 



\section{ACKNOWLEDGMENTS}

This research used resources at the Low Activation Materials Development and Analysis (LAMDA) laboratory operated by the Oak Ridge National Laboratory. Funding for this research was provided by the US Department of Energy, Office of Nuclear Energy Nuclear Science User Facility. This research was performed, in part, using instrumentation provided by the Department of Energy, Office of Nuclear Energy, Fuel Cycle R\&D Program and the Nuclear Science User Facilities. This report was authored by UT-Battelle, LLC under Contract No. DE-AC05-00OR22725 with the US Department of Energy. 



\section{ACRONYMS}

$\begin{array}{ll}\text { ADF } & \text { Annular Dark Field } \\ \text { APT } & \text { Atom Probe Tomography } \\ \text { CAES } & \text { Center for Advanced Energy Studies } \\ \text { CINR } & \text { Consolidated Innovative Nuclear Research } \\ \text { DOE } & \text { Department of Energy } \\ \text { EBSD } & \text { Electron Backscattered Diffraction } \\ \text { EDS } & \text { X-ray Dispersive Spectroscopy } \\ \text { FIB } & \text { Focused Ion Beam } \\ \text { HAADF } & \text { High Angle Annular Dark Field } \\ \text { INL } & \text { Idaho National Laboratory } \\ \text { LAMDA } & \text { Low Activation Materials Development and Analysis } \\ \text { NE } & \text { Nuclear Energy } \\ \text { NSUF } & \text { Nuclear Scientific User Facility } \\ \text { ORNL } & \text { Oak Ridge National Laboratory } \\ \text { RIS } & \text { Radiation-Induced Segregation } \\ \text { SEM } & \text { Scanning Electron Microscope } \\ \text { STEM } & \text { Scanning Transmission Electron Microscope } \\ \text { TEM } & \text { Transmission Electron Microscope }\end{array}$





\section{EXECUTIVE SUMMARY}

This document outlines the user supported post-irradiation characterization by Oak Ridge National Laboratory under the Nuclear Scientific User Facility Consolidated Innovative Nuclear Research project, "Correlative Atom Probe and Electron Microscopy Study of Radiation Induced Segregation at Low and High Angle Grain Boundaries in Steels." Fiscal Year 2018 was the second of a two-year project aimed at using analytical electron microscopy combined with atom probe tomography (APT) to probe the nanometer length scale segregations in austenitic stainless steels after neutron irradiation. Particularly, analytical electron microscopy using the FEI F200X Talos was successfully completed in the first year, and the second year was focused on APT study. Scanning electron microscopy (SEM) coupled with an electron backscatter diffraction (EBSD) detector was performed on selected specimens to locate high and low angle grain boundaries for targeted specimen preparation using focused ion beam (FIB). FIB prepared lift outs were used for APT examination of the grain boundaries using a Cameca Instruments LEAP 4000X HR instrument. This report briefly summarizes the specimen preparation and APT results obtained at the Center for Advanced Energy Studies. 



\section{INTRODUCTION}

In 2016, Oak Ridge National Laboratory (ORNL) principal investigators successfully proposed to develop a more robust understanding of the nature of defect sinks under irradiation by exploring grain boundaries in full 3D with spatial resolution less than one nanometer. The DOE Office of Nuclear Energy (NE) Nuclear Science User Facility (NSUF) provided user supported access to a combination of key facilities at ORNL and Idaho National Laboratory (INL) capable of providing scanning transmission electron microscopy (STEM) with ultra-high efficiency x-ray dispersive spectroscopy (EDS) using a $360^{\circ}$ rotation holder and atom probe tomography (APT) on irradiated austenitic core shroud materials. By studying the nature of sink-matrix interfaces, the principle investigators seek to demonstrate new techniques to gain a wider fundamental understanding of nuclear materials under elevated temperature irradiation.

The Consolidated Innovative Nuclear Research (CINR) grant provided funded access to ORNL's Low Activation Materials Development and Analysis (LAMDA) facility and laboratory technicians to identify, prepare, and survey specimens for use in the LAMDA microcopy facility. It also funds the user support on instruments including the focused ion beam (FIB) and transmission electron microscope (TEM) in the LAMDA facility. In addition, access to atom probe tomography (APT) instrument was also granted at the Center for Advanced Energy Studies. Austenitic 304 core shroud and comparative high-purity E-alloy samples were selected by the principle investigators based on a review of the available material relevant to the study. This report documents the specimen preparation, electron backscatter diffraction, and characterization in successful completion of a PICS Milestone M3UF-19OR0207132 - "Report on High Angle Grain Boundary Electron Microscopy".

\section{SPECIMEN IDENTIFICATION AND METALLOGRAPHY}

In the first year of the project, comprehensive analytical electron microscopy results have been obtained for the AS13 specimen, which was 304 steel neutron-irradiated to $5.5 \mathrm{dpa}$ at $320{ }^{\circ} \mathrm{C}$. The principle investigators strategically decided to focus atom probe tomography (APT) studies on AS13 to maximize success rate. LAMDA facility technicians located the specimen and mounted it in the correct experimental geometry. The mounted specimen was moved to a dual-beam scanning electron microscopy (SEM) - focused ion beam (FIB) to complete microstructural characterization, including identification of low angle and high angle grain boundaries using electron backscatter diffraction (EBSD), FIB lift out and APT sample preparation. The successfully prepared samples with successful APT data acquisitions are listed in Table 1.

Table 1: Samples identified for characterization

\begin{tabular}{|c|c|c|}
\hline Sample ID & Misorientation Angle & Specimen Geometry \\
\hline \hline AS13 Low Angle Grain Boundary & $3.4^{\circ}$ & Atom Probe Needle \\
\hline AS13 "High Angle" Grain Boundary & $9.1^{\circ}$ & Atom Probe Needle \\
\hline
\end{tabular}

\section{FIB-EBSD AND SPECIMEN PREPARATIONS}

\subsection{ELECTRON BACKSCATTER DIFFRACTION}

Electron backscatter diffraction (EBSD) was performed in the ORNL LAMDA FEI Versa3D DualBeam SEM-FIB instrument (FEI, Hillsboro, OR, USA) for AS13. The EBSD system is a modified version of the Oxford NordlysMax high-efficiency platform for high speed data acquisition. The data was acquired 
with a $20 \mathrm{kV} 4.0 \mathrm{nA}$ beam at a tilt of $70^{\circ}$ with a step size of $\sim 0.5 \mu \mathrm{m}$. High angle and low angle grain boundaries were selected for FIB preparation on specimen AS13. Once the desired grain boundaries were identified using EBSD, platinum straps were placed across the grain boundaries as markers for future liftout positions and to protect the sub-surface portion of the atom probe lift outs.
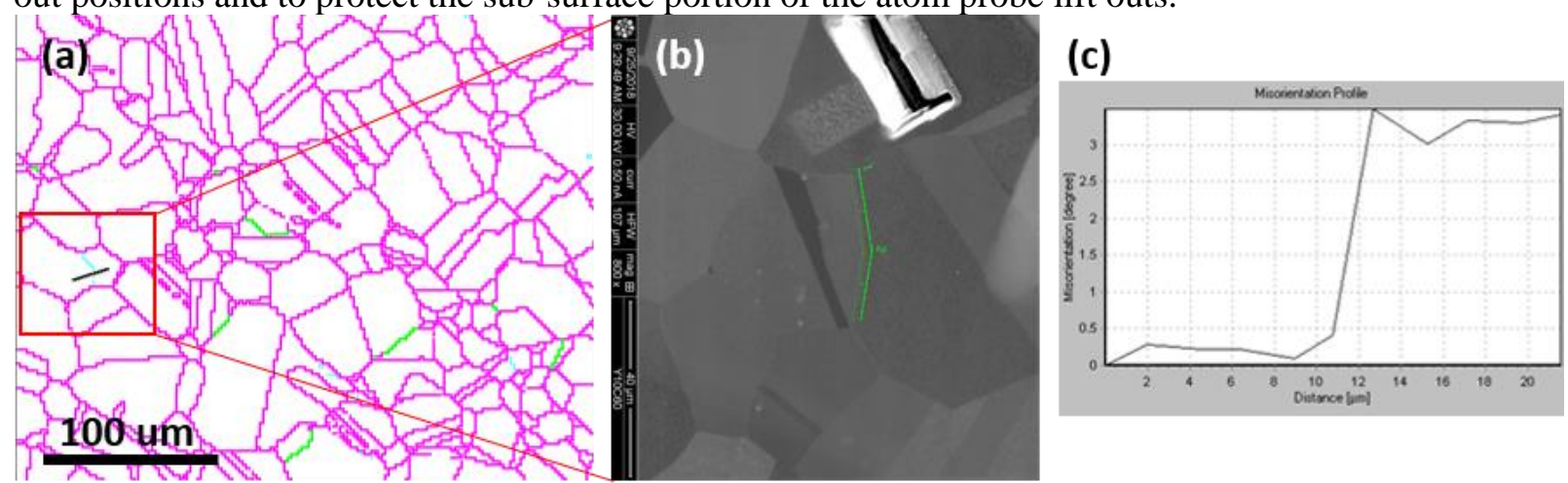

Figure 1 and 2 show selected area EBSD imagery from specimen AS13 containing low angle and high angle grain boundaries, respectively. Multiple platinum straps were laid down on each selected area, though not all led to high-quality APT needles containing the grain boundary portions.
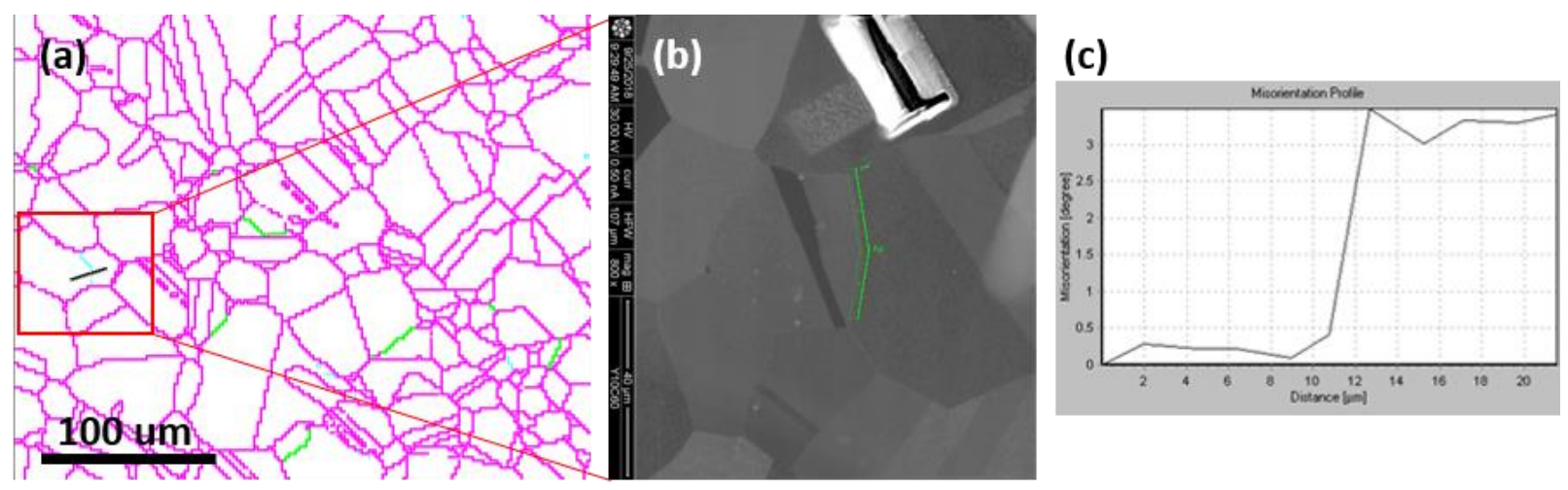

Figure 1: (a). Selected area EBSD map of CINR specimen AS13 to locate suitable low angle grain boundaries (LAGBs). (b). Enlarged SEM view of one selected LAGB that was subsequently lifted out for APT sample preparation by FIB. (c). The misorientation angle of the selected LAGB was $3.4^{\circ}$.
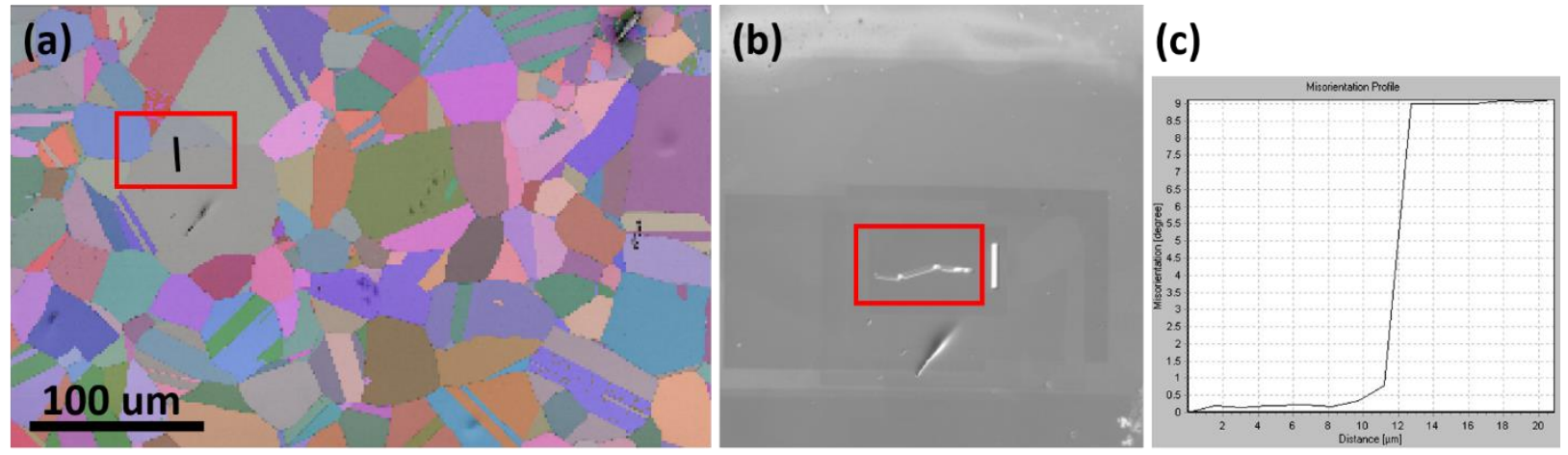

Figure 2: (a). Selected area EBSD map of CINR specimen AS13 to locate suitable high angle grain boundaries (HAGBs). (b). SEM view of one selected HAGB that was subsequently lifted out for APT sample preparation by FIB. (c). The misorientation angle of the selected "HAGB" was $9.1^{\circ}$. Note that this 
misorientation angle was lower than $15^{\circ}$ but larger than $5^{\circ}$, and its behavior differed from LAGB with misorientation angle lower than $5^{\circ}$, so it was considered HAGB in the context of this report.

\subsection{PREPARATION OF APT SAMPLES}

After grain boundaries of interest were identified and marked, four APT lift outs were created using a FEI Versa 3D DualBeam SEM-FIB and a FEI Quanta 3D 200i DualBeam SEM-FIB. APT lift outs were taken from specimen AS13 along the high angle and low angle grain boundaries. The lift outs were attached to pillars on silicon coupons made specifically for APT. Final shaping and thinning of APT needles were completed by FIB at the Center for Advanced Energy Studies (CAES), immediately followed by APT analysis in an effort to minimize surface oxidation of the samples. $360^{\circ}$ APT samples were also prepared but STEM-EDS analysis was not performed due to sample set-up and TEM holder issues.

\section{APT CHARACTERIZATION}

FIB prepared APT samples were analyzed using the Cameca Instruments LEAP 4000X HR instrument under voltage mode, which typically gives higher spatial resolution than laser mode but often having premature sample fractures. In fact, APT sample preparation and analysis were also performed for AS18 and AS23 specimens, but no APT dataset containing grain boundary was obtained due to frequent sample fractures. Only after multiple trials were successful datasets obtained for AS13 specimen.

APT analysis was conducted with sample temperature of $50 \mathrm{~K}$, pulse repetition of $200 \mathrm{kHz}$, and pulse fraction of 20\%. Cameca Integrated Visualization \& Analysis Software (IVAS) was used for APT data reconstruction and analysis. Two datasets containing grain boundaries of interests were analyzed in detail. Figure 3 shows the reconstructions of a low angle grain boundary (LAGB) with a misorientation angle of $3.4^{\circ}$ (upper row), as well as another grain boundary with misorientation angle of $9.1^{\circ}$ (lower row). Since the behavior of the latter significantly differed from the former, in the context of this report we consider the latter as a high angle grain boundary (HAGB) even though it is not necessarily a random high angle grain boundary.

The differences in radiation-induced segregation (RIS) between the two boundaries can be visualized by using the isosurface representation for varying elements at the same atomic concentration, i.e., comparing images in upper row with corresponding images in lower row. For example, the HAGB shows apparent enrichment of $\mathrm{Ni}, \mathrm{Si}, \mathrm{P}$ and depletion of $\mathrm{Cr}$ and $\mathrm{Mn}$ at GB, whereas LAGB only shows slight depletion of $\mathrm{Cr}$ and $\mathrm{Mn}$ at $\mathrm{GB}$ with no marked enrichment of $\mathrm{Ni}, \mathrm{Si}$, or P. In an effort to visualize the GB more clearly, especially in the case of LAGB, overlays of Cr-Ni-Si isosurface were also created for LAGB and HAGB, respectively. One can see that in the area where there is Cr depletion, concomitant Si enrichment takes place for both LAGB and HAGB, with the "grain boundary plane" more well-defined for HAGB.

The APT data analysis from the AS13 sample, Figure 3, shows the expected RIS analysis based on the previous findings by Field et al. [1] and the first report of this research effort [2]. Grain boundaries were enriched in $\mathrm{Ni}$ and $\mathrm{Si}$ while depleted in $\mathrm{Fe}$ and $\mathrm{Cr}$. The images also show the formation of Ni-Si rich clusters observed within the grains of the specimens although a distinct denuded zone can be observed in the vicinity of the high angle grain boundary in the AS13 sample. The Ni-Si clusters are found to be randomly distributed throughout the matrix. It is assumed the clusters are either $\gamma^{\prime}\left(\mathrm{Ni}_{3} \mathrm{Si}\right)$ or G-phase $\left(\mathrm{M}_{6} \mathrm{Ni}_{16} \mathrm{Si}_{7}\right)$ based on insights from a previous study [3]. Although detailed analysis for clusters is not the focus of the current study, it will be completed and reported later.

In addition to qualitative and phenomenological representation of RIS in LAGB and HAGB shown in Figure 3, APT data also enables accurate chemical analysis by running a typically cylinder region of interest (ROI) across the GB. A $10 \mathrm{~nm}$ (diameter) * $20 \mathrm{~nm}$ (height) ROI was used herein, enabling 
quantification of RIS by plotting then changing concentration of alloying elements as a function of distance from the approximate grain boundary plane, as shown in Figure 4. Line profiles show the expected 'w-profile' for the RIS response in this alloy based on previous work [1]. Interestingly, marked differences are observed in the magnitude of the RIS response (e.g., $\mathrm{Cr}, \mathrm{Ni}, \mathrm{Si}$ ) between the two different grain boundary types, seemingly contradicting previous STEM-EDS work [1]. In addition, subtle differences also exist for minor alloying elements: no apparent RIS of Mn in LAGB, whereas surprisingly more marked RIS of $\mathrm{Cu}$ can be seen in LAGB compared to HAGB. The key is for the current APT study, very low angle grain boundaries $\left(<5^{\circ}\right)$ were meticulously selected and analyzed, indicating the validity of the proposed mechanism of RIS to grain boundary dislocation cores.

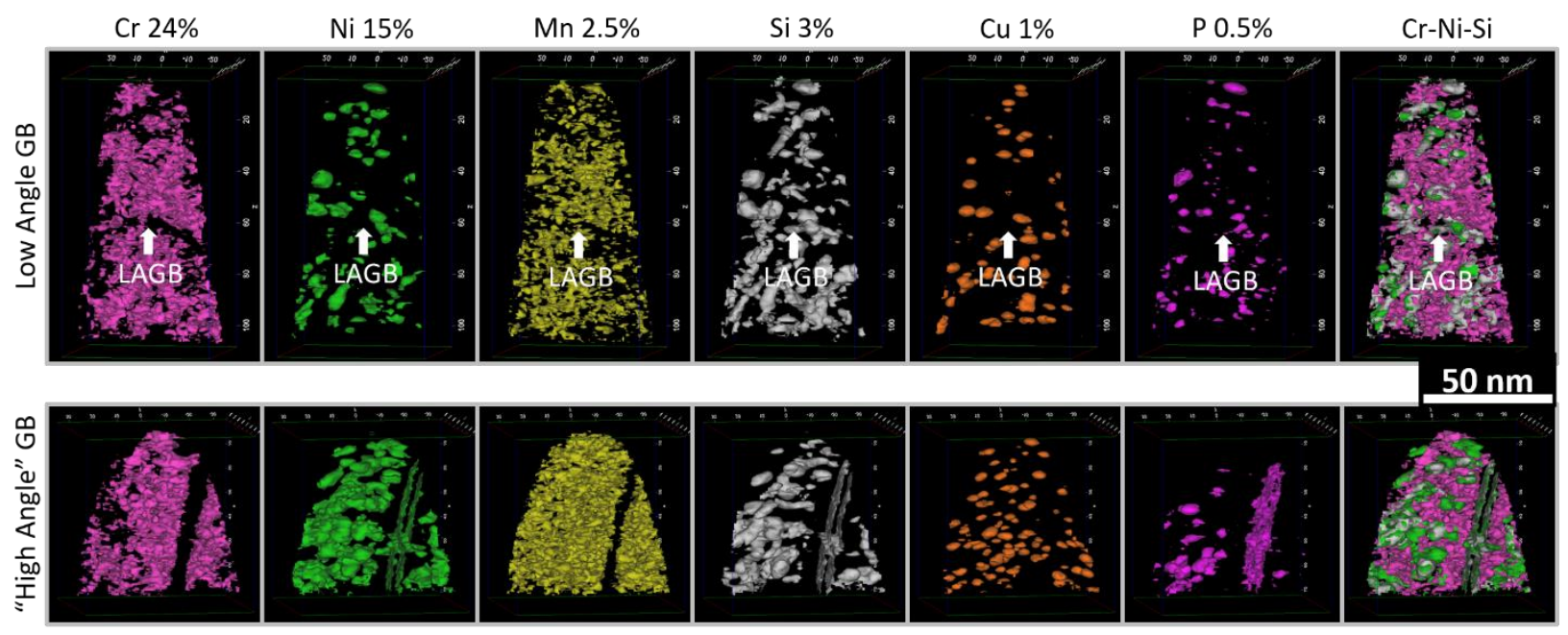

Figure 3: Reconstructions of APT datasets, represented by the isosurface of major and minor alloying elements at varying atomic concentrations, i.e., $\mathrm{Cr}$ at $24 \%, \mathrm{Ni}$ at $15 \%, \mathrm{Mn}$ at $2.5 \%, \mathrm{Si}$ at $3 \%, \mathrm{Cu}$ at $1 \%, \mathrm{P}$ at $0.5 \%$, as well as overlays of $\mathrm{Cr}-\mathrm{Ni}-\mathrm{Si}$ to better reveal the profile of grain boundaries. Upper row: low angle grain boundary, the white arrow points to the approximate location of the grain boundary; Lower row: "high angle" grain boundary. 

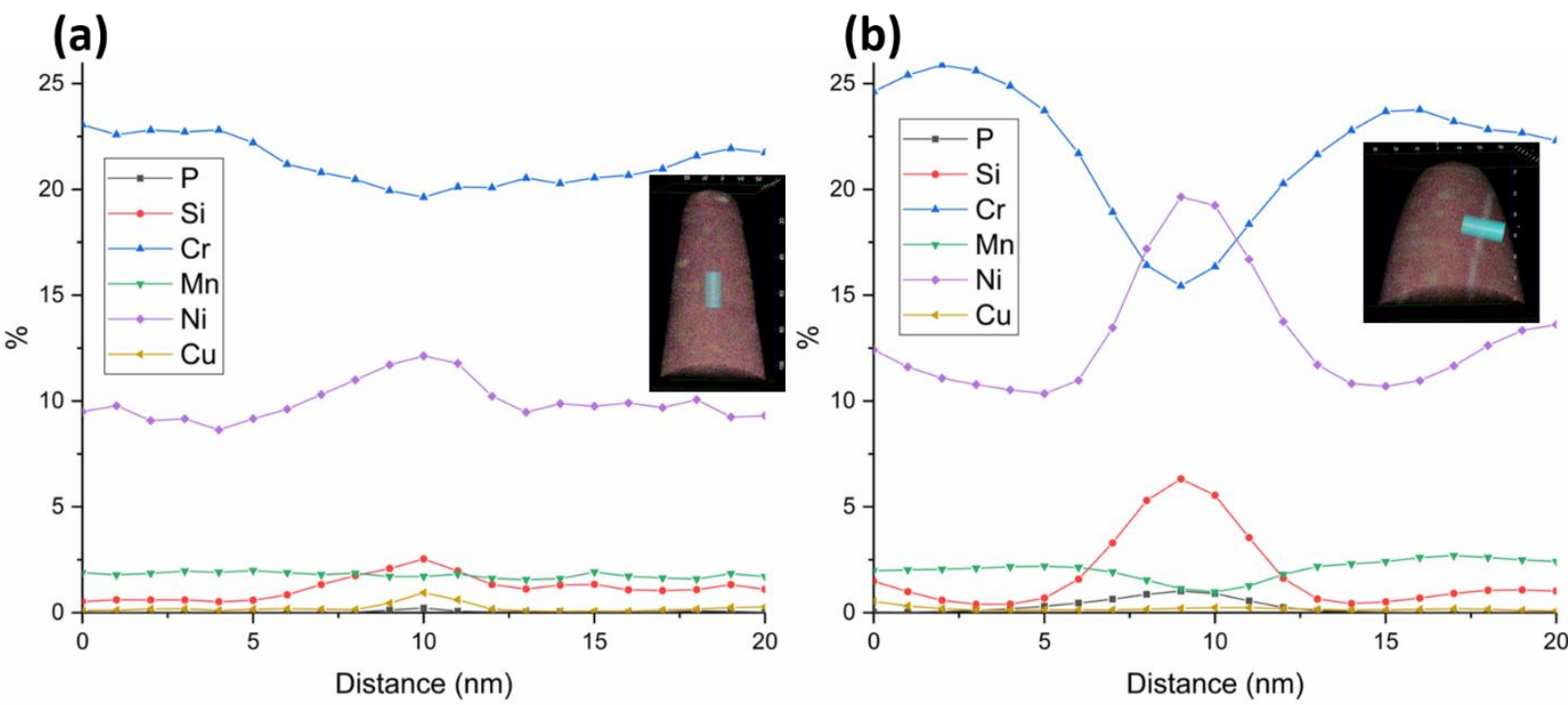

Figure 4: Quantification of radiation induced segregation (RIS) by intersecting grain boundary with a 10 $\mathrm{nm}$ (diameter) * $20 \mathrm{~nm}$ (height) cylinder region of interest (ROI), then plotting the concentration of alloying elements as a function of distance from the approximate grain boundary plane. (a). LAGB, see the ROI cylinder nearly at the center of reconstruction volume in the insert; (b). HAGB, the ROI cylinder at the center-right of the reconstruction volume in the insert.

\section{CONCLUSION AND FURTHER ANALYSIS}

The successful completion of 2018 NSUF Milestone "Report on High Angle Grain Boundary Electron Microscopy" included user supported specimen identification, mounts, EBSD, FIB, and APT. ORNL laboratory technicians and microscopy support staff prepared samples and provided multiple APT lift outs to principle investigators to study grain boundaries using atom probe tomography. More rigorous APT data analysis using in house-developed codes is ongoing with the goal of revealing the fine details of RIS to grain boundary dislocation network in the case of very low grain boundaries.

\section{REFERENCES}

[1] K.G. Field, Y. Yang, T.R. Allen, J.T. Busby, Acta Materialia 89(Supplement C) (2015) 438-449.

[2] K. Field, D. Zhang, Q. Smith, K. Linton, Radiation Induced Segregation at Low Angle Grain Boundaries in Steels: NSUF 2017 Milestone Report, Oak Ridge National Lab.(ORNL), Oak Ridge, TN (United States), 2017.

[3] Z. Jiao, G.S. Was, Acta Materialia 59(3) (2011) 1220-1238. 